\title{
Thermochemistry of strontium incorporation in aragonite from atomistic simulations
}

\author{
Sergio E. Ruiz-Hernandez ${ }^{\text {a,b,c }}$, Ricardo Grau-Crespo ${ }^{\text {b,* }}$, A. Rabdel Ruiz-Salvador ${ }^{\text {c,* }}$, \\ Nora H. De Leeuw ${ }^{b}$ \\ ${ }^{a}$ National Aquarium of Cuba, Ave. 3ra, Esquina 62, Miramar, Havana, Cuba \\ ${ }^{\mathrm{b}}$ Department of Chemistry, University College London, 20 Gordon Street, London WC1H 0AJ, UK \\ ${ }^{\mathrm{c}}$ Zeolites Engineering Laboratory, Institute of Materials Research and Engineering (IMRE), University of Havana, Havana 10400, Cuba
}

Received 16 July 2009; accepted in revised form 10 October 2009; available online 10 November 2009

\begin{abstract}
We have investigated the thermodynamics of mixing between aragonite (orthorhombic $\left.\mathrm{CaCO}_{3}\right)$ and strontianite $\left(\mathrm{SrCO}_{3}\right)$. In agreement with experiment, our simulations predict that there is a miscibility gap between the two solids at ambient conditions. All $\mathrm{Sr}_{x} \mathrm{Ca}_{1-x} \mathrm{CO}_{3}$ solids with compositions $0.12<x<0.87$ are metastable with respect to separation into a Ca-rich and a Sr-rich phase. The concentration of $\mathrm{Sr}$ in coral aragonites $(x \sim 0.01)$ lies in the miscibility region of the phase diagram, and therefore formation of separated Sr-rich phases in coral aragonites is not thermodynamically favorable. The miscibility gap disappears at around $380 \mathrm{~K}$. The enthalpy of mixing, which is positive and nearly symmetric with respect to $x=0.5$, is the dominant contribution to the excess free energy, while the vibrational and configurational entropic contributions are small and of opposite sign. We provide a detailed comparison of our simulation results with available experimental data.
\end{abstract}

(c) 2009 Elsevier Ltd. All rights reserved.

\section{INTRODUCTION}

Aragonite is one of the three polymorphs of anhydrous calcium carbonate $\left(\mathrm{CaCO}_{3}\right)$, which also include calcite and vaterite. Although calcite is the most stable $\mathrm{CaCO}_{3}$ phase at Earth surface conditions, aragonite is still a very common mineral, of both geological and biological origin. In particular, aragonite is the major constituent of coral reefs, shells, pearls and other biominerals, where it grows preferentially at ambient conditions due to the effect of organic templates (Morse and Mackenzie, 1990). Strontium is always present in coral aragonites, and it is well established that the precise $\mathrm{Sr} / \mathrm{Ca}$ ratio in the coral skeleton (typically around $9 \times 10^{-3}$ ) exhibits an inverse correlation with the seawater temperature

\footnotetext{
* Corresponding authors. Tel.: +44 207679 1083; fax: +44 20 76797463 (R. Grau-Crespo).

E-mail addresses: r.grau-crespo@ucl.ac.uk (R. Grau-Crespo), rabdel@fisica.uh.cu (A.R. Ruiz-Salvador).
}

during its biomineralization (Weber, 1973; Smith et al., 1979; De Villiers et al., 1994). This correlation has led to the use of $\mathrm{Sr} / \mathrm{Ca}$ ratios in scleractinian corals in the estimation of past sea surface temperatures for the reconstruction of global climate change (Beck et al., 1992; Guilderson et al., 1994; McCulloch et al., 1994), but the mechanism of Sr incorporation in aragonite and the cause of the temperature dependence are not yet clear, which has led to doubts of the validity of these estimations (Schrag and Linsley, 2002). Beck et al. (1992) have claimed that the coral $\mathrm{Sr} / \mathrm{Ca}$ ratio is controlled by the $\mathrm{Sr} / \mathrm{Ca}$ ratio in seawater (which is practically constant at $\sim 8.6 \times 10^{-3}$ ) and the $\mathrm{Sr} / \mathrm{Ca}$ distribution coefficient between aragonite and seawater, which depends on temperature. However, recent work by other authors suggest that the Sr incorporation in aragonite involves more complicated biological mechanisms and therefore is not thermodynamically controlled (Levi et al., 1998).

It was proposed early on that $\mathrm{Sr}$ occupies bulk lattice positions (substituting $\mathrm{Ca}$ ) in the aragonite structure (Amiel et al., 1973). However, X-ray absorption spectroscopy studies by 
Greegor et al. (1997) suggested that in scleractinian corals with overall $\mathrm{Sr} / \mathrm{Ca}$ molar ratios of about $8.6 \times 10^{-3}$, only $60 \%$ of the $\mathrm{Sr}$ was in the aragonite lattice, while the remaining $40 \%$ resided in strontianite $\left(\mathrm{SrCO}_{3}\right)$, which is iso-structural to aragonite. As the authors pointed out, the $\mathrm{Sr}$ concentration in the aragonite phase is then within the limits of thermodynamic stability of the $\mathrm{Sr}_{x} \mathrm{Ca}_{1-x} \mathrm{CO}_{3}$ solid solution with respect to phase separation, as determined by Plummer and Busenberg (1987), who found a miscibility gap in the range $5.8 \times 10^{-3}<x<0.875$ at room temperature. The presence of strontianite in the coral skeleton has been disputed by other authors, who have found no evidence of a Sr-rich phase in a wide range of corals, using similar characterization techniques (Finch and Allison, 2003; Finch et al., 2003; Allison et al., 2005). The implication of the latter group of studies, if the miscibility gap determined by Plummer and Busenberg (1987) is accepted, is that coral aragonite has a metastable $\mathrm{Sr} /$ Ca ratio, which would be kept for millions of years because of the slow cation diffusion kinetics at ambient conditions. This is indeed a plausible scenario. However, as discussed below, thermochemical studies by other authors indicate that the limit of stable substitutional $\mathrm{Sr}$ in aragonite at ambient conditions is much higher, around $0.10-0.14$, which would mean that $\mathrm{Sr}$ content in coral aragonite is thermodynamically stable with respect to phase separation.

In this work we investigate the thermodynamics of $\mathrm{Sr}$ incorporation in aragonite (structure shown in Fig. 1) using atomistic simulation techniques in combination with statistical mechanics. Our approach is fully predictive, in that no use of experimental information has been made (except, of

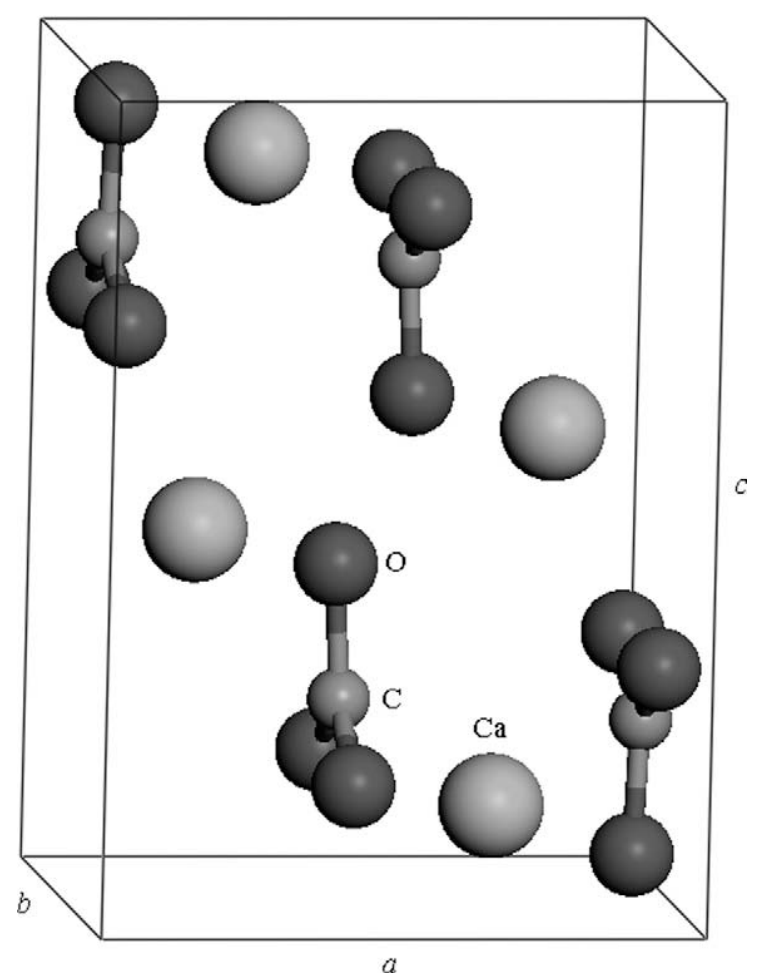

Fig. 1. The orthorhombic unit cell of aragonite (space group Pnma). course, in the original derivation of the interatomic force field). Our main aim is to produce a theoretical estimate of the maximum $\mathrm{Sr}$ content that is thermodynamically stable in aragonite. Our investigation will also allow us to reach a microscopic-level understanding of the factors controlling the stability of $\mathrm{Sr}$ impurities in the aragonite structure.

\section{METHODOLOGY}

\subsection{Evaluation of energies and free energies and geometry predictions}

Our energy calculations are based on the Born model of solids (Born and Huang, 1954) which assumes that the ions in the crystal interact via long-range electrostatic forces and short-range forces, including both the repulsions and the van der Waals attractions between neighboring electron charge clouds. The electronic polarizability of the ions is included via the shell model of Dick and Overhauser (1958), in which each polarizable ion, in our case the oxygen ion, is represented by a core and a massless shell, connected by a spring. The spring constant and the charges of the core and shell determine the polarizability of the modeled ion. The functional forms of the interatomic potentials are discussed elsewhere (e.g. Catlow, 1997). The $\mathrm{CaCO}_{3}$ potential parameters employed in this study were originally derived by Pavese et al. (1992), and were slightly modified later for a better description of the covalent bonding in the carbonate ion (Pavese et al., 1996). It was found that they correctly describe the vibrational and thermal properties of both calcite and aragonite (Pavese et al., 1992, 1996; Catti et al., 1993). A compatible $\mathrm{SrCO}_{3}$ potential was derived by De Leeuw et al. (2002) and was used by these authors in the simulation of the incorporation of $\mathrm{Sr}$ impurities in calcite surfaces and bulk (see also De Leeuw, 2002). A summary of all the potential parameters is given in Table 1 .

The lattice energies, as defined by the interatomic potentials, were calculated with the GULP code (Gale, 1997, 2005; Gale and Rohl, 2003). In order to make geometry predictions, the lattice energies are minimized with respect to the structural parameters, until the forces acting on the ions are all less than $0.001 \mathrm{eV}^{-1}$. All structures reported are the result of constant pressure energy minimizations, where not only the ionic positions but also the cell parameters are allowed to vary to find the energy minimum. The external pressure was set to zero in all calculations. Table 2 shows a comparison of the calculated and experimental cell parameters for pure aragonite and strontianite. The theoretical predictions are within $3 \%$ of the experimental values.

Finally, since we aim to simulate the behavior of the material at finite temperatures, vibrational contributions to the free energy were also obtained for each relaxed structure, by calculating the phonon frequencies in a mesh of points in the Brillouin zone (Dove, 1993), as implemented in the GULP code. The convergence of the free energy contributions with respect to the reciprocal space partition was carefully checked for pure aragonite and strontianite. We found that in both cases a $5 \times 5 \times 5$ mesh of $k$-points is enough to achieve convergence within $0.2 \mathrm{~kJ} / \mathrm{mol}$ in the unit 
Table 1

Interatomic potential parameters used in this work. A cutoff distance of $20 \AA$ was applied to all the short-range potentials.

\begin{tabular}{|c|c|c|c|}
\hline \multirow[t]{2}{*}{ Species } & \multicolumn{2}{|c|}{ Charge (e) } & \multirow[t]{2}{*}{ Spring constant $\left(\mathrm{eV} \AA^{-2}\right)$} \\
\hline & Core & Shell & \\
\hline $\mathrm{Ca}, \mathrm{Sr}$ & +2.0 & - & - \\
\hline $\mathrm{C}$ & +1.135 & - & - \\
\hline $\mathrm{O}$ & +0.587 & -1.632 & 507.4 \\
\hline Morse potential & $D(\mathrm{eV})$ & $\alpha\left(\AA^{-1}\right)$ & $r_{0}(\AA)$ \\
\hline $\mathrm{C}-\mathrm{O}_{\text {shell }}$ & 4.71 & 3.8 & 1.18 \\
\hline Buckingham potential & $A(\mathrm{eV})$ & $\rho(\AA)$ & $C\left(\mathrm{eV} \AA^{6}\right)$ \\
\hline $\mathrm{Ca}-\mathrm{O}_{\text {shell }}$ & 1550.0 & 0.29700 & 0.0 \\
\hline $\mathrm{Sr}-\mathrm{O}_{\text {shell }}$ & 1153.5 & 0.32200 & 0.0 \\
\hline $\mathrm{O}_{\text {shell }}-\mathrm{O}_{\text {shell }}$ & 16372.0 & 0.21300 & 3.47 \\
\hline Three-body potential & & $k\left(\mathrm{eV} \mathrm{rad}^{-2}\right)$ & $\Theta_{0}$ \\
\hline $\mathrm{O}_{\text {core }}-\mathrm{C}-\mathrm{O}_{\text {core }}$ & & 1.690 & 120.0 \\
\hline Four-body potential & $n$ & $k\left(\mathrm{eV} \mathrm{rad}^{-2}\right)$ & $\Theta_{0}$ \\
\hline $\mathrm{C}-\mathrm{O}_{\text {core }}-\mathrm{O}_{\text {core }}-\mathrm{O}_{\text {core }}$ & 2.0 & 0.1129 & 180.0 \\
\hline
\end{tabular}

Table 2

Experimental (De Villiers, 1971) and theoretical cell parameters of orthorhombic aragonite $\left(\mathrm{CaCO}_{3}\right)$ and strontianite $(\mathrm{SrCO})_{3}$. The angles $\alpha=\beta=\gamma=90^{\circ}$ are correctly reproduced by the calculations.

\begin{tabular}{|c|c|c|c|c|c|c|c|}
\hline \multirow[t]{2}{*}{ Mineral } & \multirow[t]{2}{*}{ Space group } & \multicolumn{2}{|l|}{$a / \AA$} & \multicolumn{2}{|l|}{$b / \AA$} & \multicolumn{2}{|l|}{$c / \AA$} \\
\hline & & Exp. & Theo. & Exp. & Theo. & Exp. & Theo. \\
\hline Aragonite & Pnma (62) & 5.740 & 5.791 & 4.961 & 4.831 & 7.967 & 7.836 \\
\hline Strontianite & Pnma (62) & 5.997 & 6.100 & 5.090 & 4.946 & 8.358 & 8.110 \\
\hline
\end{tabular}

cells, and we therefore keep the same or higher $k$-point densities in all our calculations (larger supercells require fewer $k$-points to achieve the same mesh density in the reciprocal space). In principle, it is also possible to account for thermal effects on the structure of each configuration by performing a free energy minimization at each geometry and temperature, using the quasi-harmonic approximation (e.g. Taylor et al., 1997; Gale, 1998; Grau-Crespo et al., 2002). However, considering the large number of configurations treated here and the high computational cost of free energy minimizations, we have optimized the structures only with respect to the lattice energy. The vibrational free energies were then obtained in the harmonic approximation at the energy-minimized structures, without further optimization. Although this approach does not account for structural effects of thermal origin, like thermal expansion, it can be expected to be adequate for the investigation of the vibrational energetic contributions to the mixing thermodynamics.

\subsection{Configurational statistics}

The distribution of $\mathrm{Sr}$ in the aragonite lattice was investigated utilizing the SOD (Site Occupancy Disorder) code (Grau-Crespo et al., 2007), which generates the complete configurational space for each composition in a supercell of the structure, before extracting the subspace of symmetrically inequivalent configurations, which are the ones calculated in GULP. The criterion for the equivalence of two configurations is the existence of an isometric transfor- mation that converts one configuration into the other, where the transformations considered are simply the symmetry operators of the parent structure (the structure from which all configurations are derived via site substitutions). Once the configurational spectrum is obtained, it is possible to derive configurational entropies and free energies. The methodology is based on the assumption that the extent of occurrence of one particular configuration in the disordered solid can be described by a Boltzmann-like probability which can be calculated from the vibrational free energy $G_{m}$ of the configuration, and its degeneracy $\Omega_{m}$ (the number of times that the configuration is repeated in the complete configurational space):

$P_{m}=\frac{1}{Z} \Omega_{m} \exp \left(-G_{m} / k_{B} T\right)=\frac{1}{Z} \exp \left(-G_{m}^{*} / k_{B} T\right)$

where $m=1, \ldots, M$ ( $M$ is the number of inequivalent configurations), $k_{B}$ is Boltzmann's constant (it is formally equivalent to use the gas constant $R$ instead, but we follow here the usual notation in statistical mechanics),

$Z=\sum_{m=1}^{M} \exp \left(-G_{m}^{*} / k_{B} T\right)$

is the partition function, and we have introduced the reduced free energy:

$G_{m}^{*}=G_{m}-T S_{m}^{*}$

which contains contributions from both the vibrational entropy and from the degeneracy entropy of the configuration: 
$S_{m}^{*}=k_{B} T \ln \Omega_{m}$

The configurational free energy $G$ of the disordered solid can be obtained directly from the partition function:

$G=-k_{B} T \ln Z$

and any average observable, including the enthalpy $H$ of the solution, can be estimated using configurational averaging:

$H=\sum_{m=1}^{M} P_{m} H_{m}$

In our case, since no external pressure is considered, the enthalpy is simply the energy of each configuration. The configurational entropy at any temperature and composition can then be obtained as:

$S=\frac{H-G}{T}=-k_{B} \sum_{m=1}^{M} P_{m} \ln P_{m}+\sum_{m=1}^{M} P_{m} S_{m}^{*}$

We can therefore obtain the free energy of a solid solution, including energetic, vibrational and configurational effects, by obtaining first the configurational spectrum of energies in the supercell of the structure. The total number of configurations, and the number of inequivalent ones for each composition in the $2 \times 2 \times 1$ and the $2 \times 2 \times 2$ supercells are given in Table 3 . The number of configurations scales very quickly with the size of the supercell. We will show below that our results are well converged with respect to the supercell size, as very similar results are obtained with both supercells. This type of methodology, with some variations, has been applied successfully in the simulation of the thermodynamics of mineral solid solutions (Becker et al., 2000; Lavrentiev et al., 2003; Todorov et al., 2004) and the investigation of cation distributions in oxide materials (Grau-Crespo et al., 2003, 2004; Benny et al., 2009).

Table 3

Total number of configurations $(N)$ and number of symmetrically inequivalent configurations $(M)$ for each composition $\mathrm{Sr}_{x} \mathrm{Ca}_{1-x} \mathrm{CO}_{3}$ in the $2 \times 2 \times 1\left((\mathrm{~A}, \mathrm{~B})_{16}\left(\mathrm{CO}_{3}\right)_{16}\right)$ and $2 \times 2 \times 2\left((\mathrm{~A}, \mathrm{~B})_{32}\left(\mathrm{CO}_{3}\right)_{32}\right)$ supercells. A and $\mathrm{B}$ stand for either $\mathrm{Ca}$ or $\mathrm{Sr}$.

\begin{tabular}{llrr}
\hline Cell composition & $x$ or $1-x$ & \multicolumn{1}{r}{} & \multicolumn{1}{r}{$M$} \\
\hline $\mathrm{A}_{16}\left(\mathrm{CO}_{3}\right)_{16}$ & 0 & 1 & 1 \\
$\left.\mathrm{~A}_{15} \mathrm{~B}_{(} \mathrm{CO}_{3}\right)_{16}$ & 0.063 & 16 & 1 \\
$\mathrm{~A}_{14} \mathrm{~B}_{2}\left(\mathrm{CO}_{3}\right)_{16}$ & 0.125 & 120 & 9 \\
$\mathrm{~A}_{13} \mathrm{~B}_{3}\left(\mathrm{CO}_{3}\right)_{16}$ & 0.188 & 560 & 23 \\
$\mathrm{~A}_{12} \mathrm{~B}_{4}\left(\mathrm{CO}_{3}\right)_{16}$ & 0.250 & 1820 & 82 \\
$\mathrm{~A}_{11} \mathrm{~B}_{5}\left(\mathrm{CO}_{3}\right)_{16}$ & 0.313 & 4368 & 157 \\
$\mathrm{~A}_{10} \mathrm{~B}_{6}\left(\mathrm{CO}_{3}\right)_{16}$ & 0.375 & 8008 & 303 \\
$\mathrm{~A}_{9} \mathrm{~B}_{7}\left(\mathrm{CO}_{3}\right)_{16}$ & 0.438 & 11,440 & 395 \\
$\mathrm{~A}_{8} \mathrm{~B}_{8}\left(\mathrm{CO}_{3}\right)_{16}$ & 0.500 & 12,870 & 474 \\
$\mathrm{~A}_{32}\left(\mathrm{CO}_{3}\right)_{32}$ & 0 & 1 & 1 \\
$\left.\mathrm{~A}_{31} \mathrm{~B}_{(} \mathrm{CO}_{3}\right)_{32}$ & 0.031 & 32 & 1 \\
$\mathrm{~A}_{30} \mathrm{~B}_{2}\left(\mathrm{CO}_{3}\right)_{32}$ & 0.063 & 496 & 17 \\
$\mathrm{~A}_{29} \mathrm{~B}_{3}\left(\mathrm{CO}_{3}\right)_{32}$ & 0.094 & 4960 & 99 \\
$\mathrm{~A}_{28} \mathrm{~B}_{4}\left(\mathrm{CO}_{3}\right)_{32}$ & 0.125 & 35,960 & 694 \\
\hline
\end{tabular}

\subsection{Evaluation of the mixing thermodynamic potentials}

Having obtained the enthalpy and free energy of the solid solution, it is useful to evaluate the enthalpy of mixing:

$$
\begin{aligned}
\Delta H_{\text {mix }}= & H\left[\mathrm{Sr}_{x} \mathrm{Ca}_{1-x} \mathrm{CO}_{3}\right]-(1-x) H\left[\mathrm{CaCO}_{3}\right] \\
& -x H\left[\mathrm{SrCO}_{3}\right]
\end{aligned}
$$

which can be compared with experimental calorimetric determinations, and the free energy of mixing:

$$
\begin{aligned}
\Delta G_{\text {mix }}= & G\left[\mathrm{Sr}_{x} \mathrm{Ca}_{1-x} \mathrm{CO}_{3}\right]-(1-x) G\left[\mathrm{CaCO}_{3}\right] \\
& -x G\left[\mathrm{SrCO}_{3}\right]
\end{aligned}
$$

which can also be found experimentally from equilibrium composition measurements, e.g. using electrochemical cells. In Eqs. (8) and (9), all the energies are given per formula unit. $\Delta G_{\text {mix }}(x)$ quantifies the stability of the mixed solid with respect to the pure end-members, aragonite $\left(\mathrm{CaCO}_{3}\right)$ and strontianite $\left(\mathrm{SrCO}_{3}\right)$. It is common to report the excess free energies of the solution, defined as:

$G^{E}(x)=\Delta G_{\mathrm{mix}}-\Delta G_{\mathrm{mix}}^{\text {ideal }}$

where

$\Delta G_{\text {mix }}^{\text {ideal }}(x)=k_{B} T[x \ln x+(1-x) \ln (1-x)]$

is the free energy of mixing in an ideal solid solution, where the only contribution comes from the ideal entropy corresponding to a fully disordered solid. The excess free energy $G^{E}$ therefore contains all the non-ideal contributions to the mixing free energy: an enthalpy part $\left(\Delta H_{\text {mix }}\right)$, and an entropy part, which contains both the deviation of the configurational entropy from ideality and a contribution from the vibrational entropy of mixing. Our simulation method allows us to separate all these different contributions.

Excess free energies from experiment are commonly fitted to a polynomial of the mole fraction $x$ in the form given by Guggenheim (1937):

$G^{E}=x(1-x)\left[A_{0}+A_{1}(2 x-1)+\cdots\right]$

which can be expanded to higher orders of $2 x-1$. Different types of solid solution behavior can be expressed in terms of Eq. (12). Ideal solutions, for example, correspond to the case $A_{0}=A_{1}=A_{2}=\cdots=0$, while the case where $A_{0} \neq 0$, $A_{2}=A_{3}=\cdots=0$ is the so-called regular solution (strictly regular if $A_{0}$ does not depend on temperature, e.g. Plummer and Busenberg, 1987; Prieto et al., 2000). We will fit our calculated $G^{E}$ values to this type of polynomials in order to compare with experimental information. The fitted function will also allow us to calculate numerically the miscibility gap in the solid solution, which is marked by two minima of $\Delta G_{\text {mix }}(x)$.

\section{RESULTS AND DISCUSSION}

The equilibrium geometries and energies of the Srsubstituted configurations were calculated both without and including vibrational effects, in the $2 \times 2 \times 1$ (16 cation sites) and $2 \times 2 \times 2$ (32 cation sites) supercells of the aragonite structure. The unit cell of aragonite contains four cation sites (Fig. 1). A list of calculated configurations is 
presented in Table 3, where $x$ determines the composition of the solid solution $\mathrm{Sr}_{x} \mathrm{Ca}_{1-x} \mathrm{CO}_{3}$. For the $2 \times 2 \times 2$ supercell, other concentrations than those shown were not considered, due to the prohibitive computational cost. It will be shown below that the use of a smaller supercell does not change the results significantly.

Because aragonite and strontianite are iso-structural, the introduction of impurity cations in either material does not affect the structure significantly beyond small local relaxations. We find that the lowest-energy Sr-doped aragonite structures are those with shorter $\mathrm{Sr}-\mathrm{Sr}$ distances, although the calculated interaction between impurities is small. We therefore do not expect that $\mathrm{Sr}$ impurities will form clusters, because at the low concentrations of interest here the number of configurations with more homogeneous Sr distributions is much larger than those exhibiting impurity aggregation, and this entropic effect is much stronger than the weak stabilization provided by the interaction between impurities. For example, the spectrum of configurations corresponding to the strontium concentration $x=0.125$, obtained with the $2 \times 2 \times 2$ supercell $\left(\mathrm{Sr}_{4} \mathrm{Ca}_{28}\left(\mathrm{CO}_{3}\right)_{32}\right)$ at $300 \mathrm{~K}$ is shown in Fig. 2, where the zero-level is defined as the reduced free energy of the most probable configuration. Nearly half of the configurations lie within $k_{B} T=2.49 \mathrm{~kJ} / \mathrm{mol}$, indicating that a great deal of disorder

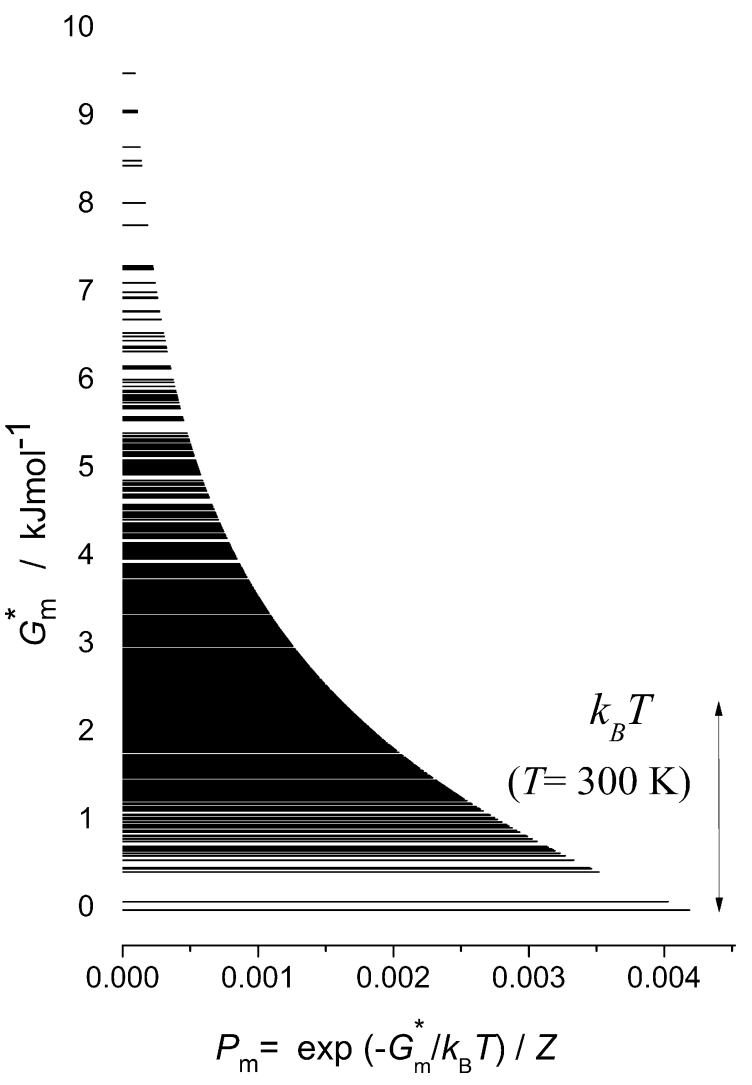

Fig. 2. Configurational spectrum of reduced free energies corresponding to the composition $\mathrm{Sr}_{0.125} \mathrm{Ca}_{0.875} \mathrm{CO}_{3}$ at $300 \mathrm{~K}$, as calculated in the $2 \times 2 \times 2$ supercell. $P_{m}$ is the probability of occurrence of the independent configuration, and $G_{m}^{*}$ is its reduced free energy. should be expected in the $\mathrm{Sr}$ distribution. However, there is some deviation from a uniform probability distribution, which will translate into a reduced configurational entropy compared with an ideal solid solution.

Fig. 3(a) shows the enthalpies of mixing as a function of Sr concentration, calculated using Eqs. (6) and (8) for both the $2 \times 2 \times 1$ and the $2 \times 2 \times 2$ supercells. The formation of the solid solution from pure aragonite and strontianite is endothermic in the whole range of compositions, as expected from the difference in ionic radii (Shannon, 1976) between $\mathrm{Ca}^{2+}(1.18 \AA)$ and $\mathrm{Sr}^{2+}(1.31 \AA)$ in ninefold coordination. Our theoretical values are not far from the calorimetric measurements by Casey et al. (1996a), especially when considering the small values involved and the wide error bars and dispersion of the experimental points. These authors fitted their data to a symmetric curve in the form:

$\Delta H_{\text {mix }}=W x(1-x)$

and found $W=13.5 \mathrm{~kJ} / \mathrm{mol}$. We will argue below that this value of $W$ is probably too high, not only in comparison with our calculations but also in the light of experimental determinations of mixing free energies by the same and other authors. Using the same model to fit our data from the $2 \times 2 \times 1$ supercell leads to $W=5.84 \mathrm{~kJ} / \mathrm{mol}$, although an asymmetric model in the form:
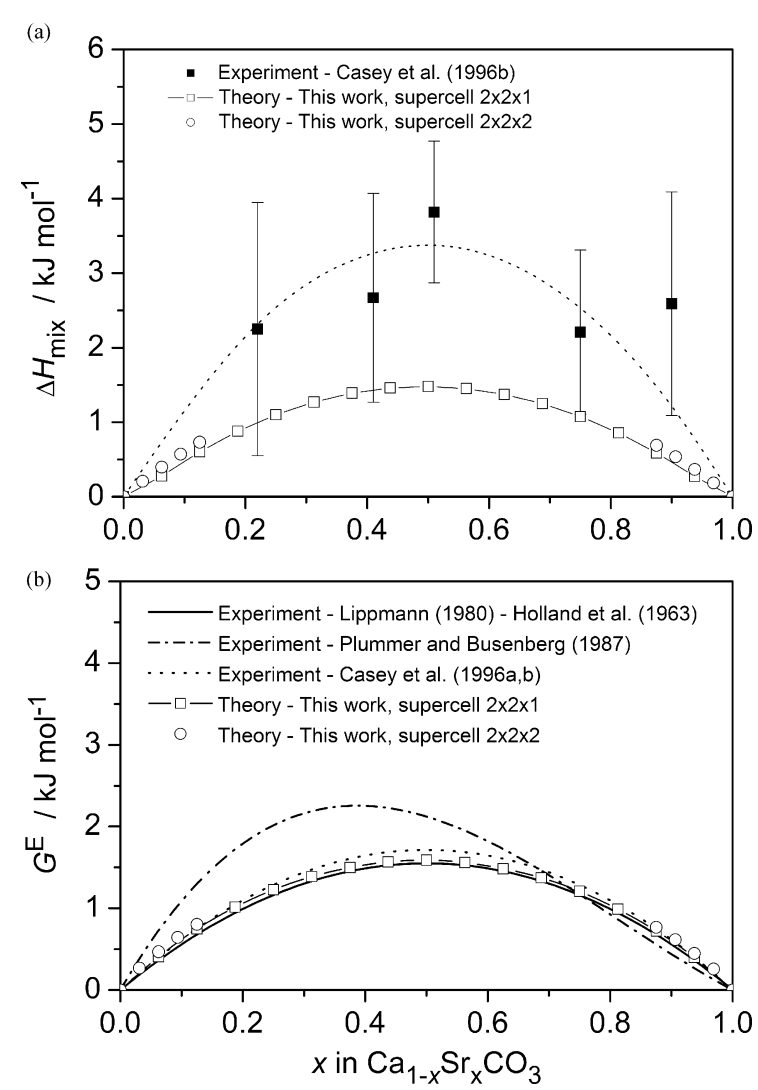

Fig. 3. Aragonite-strontianite mixing under ambient conditions. (a) Calculated and experimental enthalpies of mixing and (b) calculated and experimental excess free energies. 
$\Delta H_{\text {mix }}=x(1-x)\left[W_{0}+W_{1}(2 x-1)\right]$

with $W_{0}=5.84 \mathrm{~kJ} / \mathrm{mol}$ and $W_{1}=-0.12 \mathrm{~kJ} / \mathrm{mol}$ provides a better fit. The slightly asymmetric character of our $\Delta H_{\text {mix }}(x)$ curve, with small and negative $W_{1}$, means that the energetic cost of doping aragonite with $\mathrm{Sr}$ from strontianite $\left(W_{0}-W_{1}\right)$ is somewhat higher than the cost of doping strontianite with $\mathrm{Ca}$ from aragonite $\left(W_{0}+W_{1}\right)$. This asymmetry is reasonable, based on the larger ionic radius of $\mathrm{Sr}$ compared to $\mathrm{Ca}$, as the incorporation of $\mathrm{Sr}$ would lead to a larger elastic strain in the lattice of aragonite than vice versa (McLean, 1957; de Leeuw and Parker, 2000). Fig. 3(a) also shows that using the larger $2 \times 2 \times 2$ supercell does not significantly change our predicted mixing enthalpies. It should be noted here that, since $\Delta H_{\text {mix }}$ is just one of the contributions to the excess free energy, we make a distinction between $W_{0}$ and $W_{1}$ in Eq. (14), and the $A_{0}$ and $A_{1}$ parameters of the Guggenheim expression (Eq. (12)) for the excess free energy. The connection between the two sets of parameters will be discussed below.

The calculated excess free energy at $300 \mathrm{~K}$ is shown in Fig. 3(b), together with experimental determinations (fitting curves) by other authors. Our fitting to a Guggenheim polynomial of first order in $2 x-1$ (Eq. (12)) leads to $A_{0}=6.43 \mathrm{~kJ} / \mathrm{mol}$ and $A_{1}=-0.12 \mathrm{~kJ} / \mathrm{mol}$, which is practically symmetric around $x=0.5$ (very small $A_{1}$ value), in contrast with the strongly asymmetric curve proposed by Plummer and Busenberg (1987) to fit their experimental measurements under ambient conditions. In the picture proposed by these authors, it is much more difficult to dope aragonite with $\operatorname{Sr}\left(A_{0}-A_{1}=13 \mathrm{~kJ} / \mathrm{mol}\right)$ than strontianite with $\mathrm{Ca}\left(A_{0}+A_{1}=4 \mathrm{~kJ} / \mathrm{mol}\right)$. However, our theoretical results are in very good agreement with experimental data from other authors. Lippmann (1980), for example, treated the data obtained by Holland et al. (1963), and suggested a symmetric model with $A_{0}=6.2 \mathrm{~kJ} / \mathrm{mol}$. Also, some of the same authors who published the calorimetric study (Casey et al., 1996a), reported excess free energy measurements using an electrochemical cell (Casey et al., 1996b), and their results in this case are in very good agreement with our data.

A summary of all experimental and theoretical Guggenheim parameters is given in Table 4 . We also report there the values obtained from our simulations at 350 and $400 \mathrm{~K}$. It can be seen that, while $A_{1}$ remains constant and small, $A_{0}$ increases slightly with temperature up to $6.70 \mathrm{~kJ} / \mathrm{mol}$ at $400 \mathrm{~K}$. Using a linear interpolation for $A_{1}$

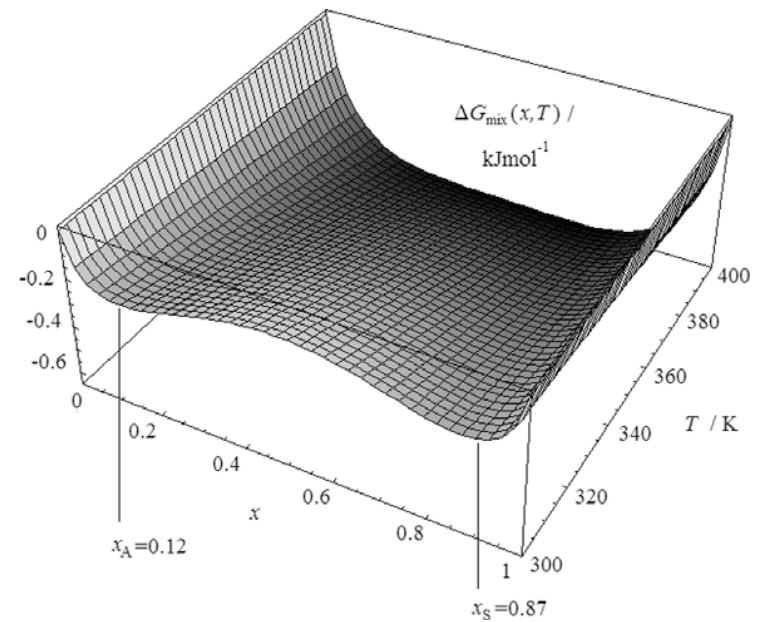

Fig. 4. Theoretical free energy of mixing as a function of temperature and composition $x$ in $\mathrm{Sr}_{x} \mathrm{Ca}_{1-x} \mathrm{CO}_{3}$. The minima $x_{\mathrm{A}}$ and $x_{\mathrm{S}}$ mark the predicted limits of the thermodynamic miscibility gap between aragonite and strontianite under ambient conditions.

we can obtain free energy of mixing curves at temperatures between 300 and $400 \mathrm{~K}$, as shown in Fig. 4. At ambient temperature, the free energy of mixing has two minima at $x_{\mathrm{A}}=0.12$ and $x_{\mathrm{S}}=0.87$, which define a miscibility gap between aragonite and strontianite. Any solid with composition $x_{\mathrm{A}}<x<x_{\mathrm{S}}$ is metastable with respect to a mechanical mixture of phases with composition $x_{\mathrm{A}}$ (Srdoped aragonite) and $x_{\mathrm{S}}$ (Ca-doped strontianite).

The prediction of a miscibility gap in the aragonitestrontianite system under ambient conditions is in agreement with most experimental studies, and with the absence of intermediate compositions in natural solid solutions (Speer, 1983). While all authors basically agree on the upper limit of the miscibility gap $\left(x_{\mathrm{S}}\right)$ being around 0.86 0.90 (our theoretical prediction is 0.87 ), the lower limit of the miscibility gap is less clear (see Table 4). Plummer and Busenberg (1987) predict a low value of equilibrium $\mathrm{Sr}$ content in aragonite $\left(x_{\mathrm{A}}=0.0058\right)$ while Lippmann (1980) and Casey et al. (1996b) predict higher values (0.10 and 0.14$)$. We note that the $\mathrm{Sr}$ content of the coral skeleton $(x \sim 0.01)$ is intermediate between the two sets of results, and therefore discrimination between the two types of behavior is important in order to elucidate the stable or metastable character of $\mathrm{Sr}$ incorporation in coral arago-

Table 4

Summary of fitting parameters for the excess free energy $G^{E}=x(1-x)\left[A_{0}+A_{1}(2 x-1)\right]$, as obtained experimentally by other authors and theoretically in this work.

\begin{tabular}{llllll}
\hline$T / \mathrm{K}$ & Reference & $A_{0} / \mathrm{kJ} \mathrm{mol}^{-1}$ & $A_{1} / \mathrm{kJ} \mathrm{mol}^{-1}$ & $x_{\mathrm{A}}$ & $x_{\mathrm{S}}$ \\
\hline 298.15 & Experimental-Lippmann (1980) and Holland et al. (1963) & 6.2 & 0 & 0.14 & 0.86 \\
& Experimental_Plummer and Busenberg (1987) & 8.48 & -4.51 & 0.0058 & 0.88 \\
& Experimental_Casey et al. (1996a,b) & 6.86 & 0 & 0.10 & 0.90 \\
300 & Theory-this work & 6.43 & -0.12 & 0.12 & 0.87 \\
& & $(6.93)^{\mathrm{a}}$ & $(-0.12)^{\mathrm{a}}$ & $(0.09)^{\mathrm{a}}$ & $(0.90)^{\mathrm{a}}$ \\
349.15 & Experimental_Plummer and Busenberg (1987) & 7.71 & -3.36 & 0.031 & 0.83 \\
350 & Theory-this work & 6.57 & -0.12 & 0.22 & 0.78 \\
400 & Theory-this work & 6.70 & -0.12 & - & - \\
\hline
\end{tabular}

${ }^{\text {a }}$ Values in parenthesis are those calculated without including vibrational contributions. 
nites. Our theoretical result (0.12) supports the second set of values, and therefore suggests that $\mathrm{Sr}$ is stable in corals with respect to phase separation. Fig. 4 also shows that the predicted miscibility gap becomes narrower with increasing temperature, and disappears completely at around $380 \mathrm{~K}$.

Let us now discuss the different contributions to the excess free energy. It is clear that the small (and temperatureindependent) effect introduced by the parameter $A_{1}$ in the excess free energy arises from the asymmetry of the enthalpy of mixing $\left(A_{1}=W_{1}\right)$. Therefore we will focus on the different contributions to $A_{0}$. By fitting the excess free energies obtained with and without vibrational contributions, we are able to do an approximate decomposition:

$A_{0}=W_{0}+\Delta A_{0}^{\mathrm{conf}}+\Delta A_{0}^{\mathrm{vib}}$

where $W_{0}=5.84 \mathrm{~kJ} / \mathrm{mol}$ is the enthalpic contribution, which remains practically constant in the temperature interval of interest here, while $\Delta A_{0}^{\text {conf }}$ and $\Delta A_{0}^{\text {vib }}$ are the configurational and vibrational entropic contributions. At $300 \mathrm{~K}$, $\Delta A_{0}^{\text {conf }}=1.09 \mathrm{~kJ} / \mathrm{mol}$ and $\Delta A_{0}^{\text {vib }}=-0.50 \mathrm{~kJ} / \mathrm{mol}$. The vibrational contribution lowers the free energies of mixing, as can be seen in Fig. 5, and the contribution becomes more negative at higher temperatures. On the other hand, the configurational contribution to the excess free energy is positive because the real configurational entropy is lower than the ideal one corresponding to full disorder, as discussed above. Therefore, since the two entropic contributions are relatively small and of opposite sign, the dominant contribution to the excess free energy becomes the enthalpy of mixing, which accounts for the similarity between the $\Delta H_{\text {mix }}(x)$ and the $G^{E}(x)$ curves in Fig. 3(a) and (b). Thus, the solid solution is nearly regular, because it has very small excess entropy. The total excess entropy should be even lower because the configurational contribution is overestimated here due to the periodicity of the simulation supercell, which imposes some constraints on the level of disorder. The present analysis indicates that the difference between the calorimetric and the free energy data of Casey et al. is unlikely to be accounted for by non-ideal entropic effects. Our theoretical simulations, together with the results published by Lippmann (1980) and Holland et al.

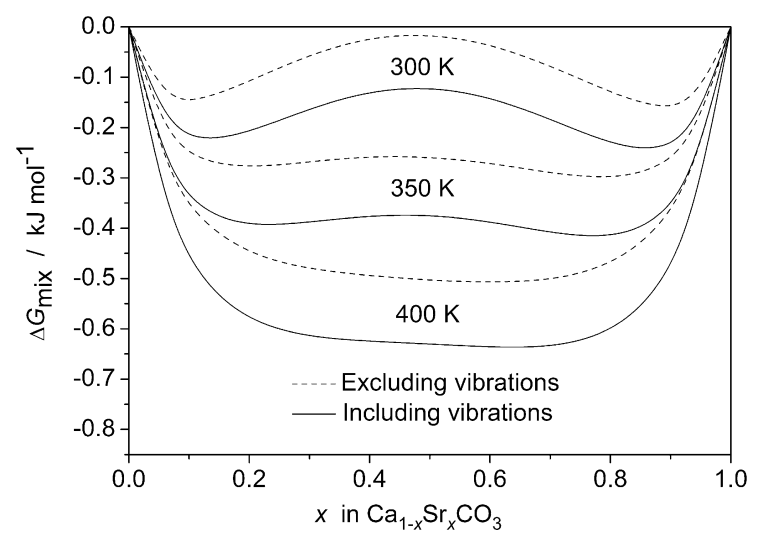

Fig. 5. Effect of vibrations on the calculated free energies of mixing at 300,350 and $400 \mathrm{~K}$.

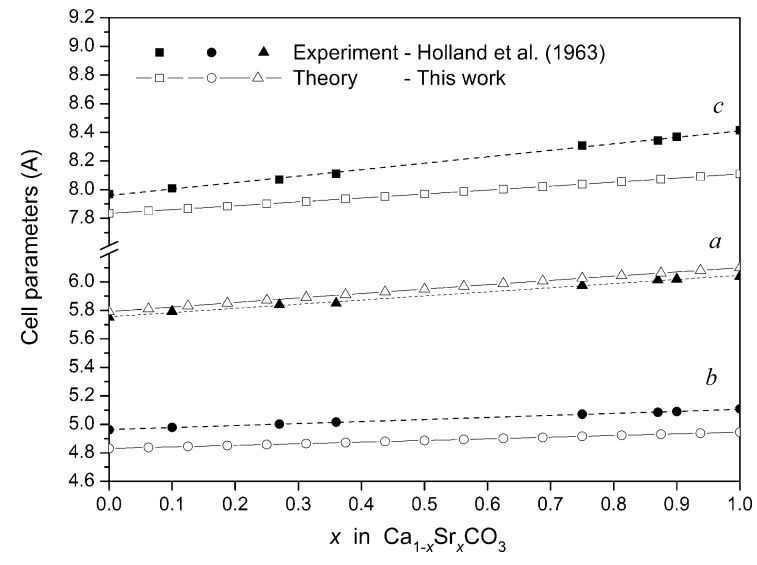

Fig. 6. Variation of the calculated cell parameters for the $\mathrm{Sr}_{x} \mathrm{Ca}_{1-x} \mathrm{CO}_{3}$ solid solution with composition, in comparison with experiment.

(1963), add support to their free energy determinations, rather than to their calorimetric measurements (Fig. 6).

We have also calculated the cell parameters in the aragonite-strontianite as a function of composition, assuming a high temperature $(400 \mathrm{~K})$ at which all compositions are stable. At each composition, the cell parameters are obtained as configurational averages:

$a=\sum_{m=1}^{M} P_{m} a_{m} ; \quad b=\sum_{m=1}^{M} P_{m} b_{m} ; \quad c=\sum_{m=1}^{M} P_{m} c_{m}$

where $a_{m}, b_{m}$ and $c_{m}$ are the cell parameters of the $m$ th independent configuration. Our data do not include thermal expansion effects as mentioned in Section 2.1. In order to avoid confusion, we note here that the aragonite and strontianite crystallographic structures are sometimes reported in the Pmen space group (No. 62), for which $a<c<b$ (e.g. Holland et al., 1963), while other authors (e.g. Lucas-Girot et al., 2007) use the Pnma setting of the same space group, for which $b<a<c$. Here we will use the latter setting. Our results show that, as expected from the larger radius of $\mathrm{Sr}^{2+}$ compared to $\mathrm{Ca}^{2+}$, all the cell parameters increase with $x$. Small departures from the linear dependences were reported by Holland et al. (1963), who found that the $a$ dimension lies slightly above and the $c$ dimension slightly below the lines joining the end-members. However, in our calculations all the cell dimensions vary linearly with composition, which is in agreement with more recent X-ray diffraction data by Lucas-Girot et al. (2007).

\section{CONCLUSIONS}

We have performed an atomistic simulation study of the mixing thermodynamics of aragonite-strontianite solid solutions in the whole range of compositions $\mathrm{Sr}_{x} \mathrm{Ca}_{1-x}$ $\mathrm{CO}_{3}$. We have shown that the dominant contribution to the excess free energy comes from the enthalpy of mixing, while the vibrational and configurational entropic contributions are small and of opposite sign. These findings, together with the nearly symmetric character of the mixing thermodynamic potentials around $x=0.5$, mean that the 
aragonite-strontianite mixing behavior is close to the regular solution model. However, the regular behavior is not strict in that (a) there is a small asymmetric contribution to the excess energy and (b) the $A_{0}$ parameter in the Guggenheim expression shows some dependence on temperature.

Our simulations predict that at room temperature and up to $\sim 380 \mathrm{~K}$, there is a miscibility gap of thermodynamic origin between aragonite and strontianite. Under ambient conditions, all $\mathrm{Sr}_{x} \mathrm{Ca}_{1-x} \mathrm{CO}_{3}$ solids with compositions $0.12<x<0.87$ are metastable with respect to separation into a Ca-rich and a Sr-rich phase, which agrees well with the results reported by Casey et al. (1996b) and also by Lippmann (1980) based on measurements by Holland et al. (1963), but is in contrast with the results of Plummer and Busenberg (1987), who suggested a much lower miscibility limit for $\mathrm{Sr}$ in aragonite (0.0058). Our results suggest that the concentration of $\mathrm{Sr}$ in coral aragonite, which is typically around 0.01 , is therefore stable in substitutional positions in the aragonite lattice, and should not experience phase separation into strontianite. We should note that, although Greegor et al. (1997) have suggested that a large fraction of $\mathrm{Sr}$ in coral skeletons resides in strontianite, more recent experiments have found no evidence of $\mathrm{Sr}$-rich phases in the coral skeletons (e.g. Allison et al., 2005). The discussion presented here is important for the interpretation of coral $\mathrm{Sr}$ paleothermometry, as the presence of $\mathrm{Sr}$ in other phases than aragonite would complicate the understanding of the correlation between coral $\mathrm{Sr} / \mathrm{Ca}$ ratios and sea surface temperatures.

\section{ACKNOWLEDGMENTS}

We acknowledge the EU-funded "Mineral Nucleation and Growth Kinetics (MIN-GRO) Marie-Curie Research and Training Network" for funding (Grant MRTNCT-2006-035488). Partial support from the University of Havana and the Cuban Environmental Agency is also gratefully acknowledged. We thank Dr. Anabel Lam and Prof. Nestor Fernandez for useful discussions.

\section{REFERENCES}

Allison N., Finch A. A., Newville M. and Sutton S. R. (2005) Strontium in coral aragonite: 3 . Sr coordination and geochemistry in relation to skeletal architecture. Geochim. Cosmochim. Acta 69(15), 3801-3811.

Amiel A. J., Friedman G. M. and Miller D. S. (1973) Distribution and nature of incorporation of trace-elements in modern aragonitic corals. Sedimentology 20(1), 47-64.

Beck J. W., Edwards R. L., Ito E., Taylor F. W., Recy J., Rougerie F., Joannot P. and Henin C. (1992) Sea-surface temperature from coral skeletal strontium calcium ratios. Science 257(5070), 644-647.

Becker U., Fernandez-Gonzalez A., Prieto M., Harrison R. and Putnis A. (2000) Direct calculation of thermodynamic properties of the barite/celestite solid solution from molecular principles. Phys. Chem. Miner. 27(4), 291-300.

Benny S., Grau-Crespo R. and De Leeuw N. H. (2009) A theoretical investigation of $\alpha-\mathrm{Fe}_{2} \mathrm{O}_{3}-\mathrm{Cr}_{2} \mathrm{O}_{3}$ solid solutions. Phys. Chem. Chem. Phys. 11, 808-815.

Born M. and Huang K. (1954) Dynamical Theory of Crystal Lattices. Oxford University Press.
Casey W. H., Chai L. A., Navrotsky A. and Rock P. A. (1996a) Thermochemistry of mixing strontianite $\left[\mathrm{SrCO}_{3}(\mathrm{~s})\right]$ and aragonite $\left[\mathrm{CaCO}_{3}(\mathrm{~s})\right]$ to form $\mathrm{Ca}_{x} \mathrm{Sr}_{1-x} \mathrm{CO}_{3}$ (s) solid solutions. Geochim. Cosmochim. Acta 60(6), 933-940.

Casey W. H., Rock P. A., Chung J. B., Walling E. M. and McBeath M. K. (1996b) Gibbs energies of formation of metal carbonate solid solutions: 2. The $\mathrm{Ca}_{x} \mathrm{Sr}_{1-x} \mathrm{CO}_{3}$ (s) system at $298 \mathrm{~K}$ and 1 bar. Am. J. Sci. 296(1), 1-22.

Catlow C. R. A. (1997) Computer Modelling in Inorganic Crystallography. Academic Press.

Catti M., Pavese A. and Price G. D. (1993) Thermodynamic properties of $\mathrm{CaCO}_{3}$ calcite and aragonite-a quasi-harmonic calculation. Phys. Chem. Miner. 19(7), 472-479.

De Leeuw N. H. (2002) Molecular dynamics simulations of the growth inhibiting effect of $\mathrm{Fe} 2+, \mathrm{Mg} 2+, \mathrm{Cd} 2+$, and $\mathrm{Sr} 2+$ on calcite crystal growth. J. Phys. Chem. B 106(20), 5241-5249.

De Leeuw N. H. and Parker S. C. (2000) Modeling absorption and segregation of magnesium and cadmium ions to calcite surfaces: Introducing $\mathrm{MgCO} 3$ and $\mathrm{CdCO} 3$ potential models. J. Chem. Phys. 112(9), 4326-4333.

De Leeuw N. H., Harding J. H. and Parker S. C. (2002) Molecular dynamics simulations of the incorporation of $\mathrm{Mg}^{2+}, \mathrm{Cd}^{2+}$ and $\mathrm{Sr}^{2+}$ at calcite growth steps: introduction of a $\mathrm{SrCO}_{3}$ potential model. Mol. Simul. 28(6-7), 573-589.

De Villiers J. P. R. (1971) Crystal structures of aragonite, strontianite and witherite. Am. Mineral. 56(5-6), 758-767.

De Villiers S., Shen G. T. and Nelson B. K. (1994) The Sr/Catemperature relationship in coralline aragonite-influence of variability in $(\mathrm{Sr} / \mathrm{Ca})$ seawater and skeletal growth-parameters. Geochim. Cosmochim. Acta 58(1), 197-208.

Dick B. G. and Overhauser A. W. (1958) Theory of the dielectric constant of alkali halide crystals. Phys. Rev. 112, 90-103.

Dove M. T. (1993) Introduction to Lattice Dynamics. Cambridge University Press.

Finch A. A. and Allison N. (2003) Strontium in coral aragonite: 2 . Sr coordination and the long-term stability of coral environmental records. Geochim. Cosmochim. Acta 67(23), 4519-4527.

Finch A. A., Allison N., Sutton S. R. and Newville M. (2003) Strontium in coral aragonite: 1 . Characterization of Sr coordination by extended absorption X-ray fine structure. Geochim. Cosmochim. Acta 67(6), 1189-1194.

Gale J. D. (1997) GULP: a computer program for the symmetryadapted simulation of solids. J. Chem. Soc.: Faraday Trans. 93(4), 629-637.

Gale J. D. (1998) Analytical free energy minimization of silica polymorphs. J. Phys. Chem. B 102, 5423-5431.

Gale J. D. (2005) GULP: capabilities and prospects. Z. Kristallogr. 220, 552-554.

Gale J. D. and Rohl A. L. (2003) The general utility lattice program (GULP). Mol. Simul. 29(5), 291-341.

Grau-Crespo R., Acuay E. and Ruiz-Salvador R. R. (2002) A free energy minimisation study of the monoclinic-orthorhombic transition in MFI zeolite. Chem. Commun. 21, 2544-2545.

Grau-Crespo R., De Leeuw N. H. and Catlow C. R. A. (2003) Cation distribution and magnetic ordering in $\mathrm{FeSbO}_{4}$. J. Mater. Chem. 13(12), 2848-2850.

Grau-Crespo R., De Leeuw N. H. and Catlow C. R. A. (2004) Distribution of cations in $\mathrm{FeSbO}_{4}$ : a computer modeling study. Chem. Mater. 16(10), 1954-1960.

Grau-Crespo R., Hamad S., Catlow C. R. A. and De Leeuw N. H. (2007) Symmetry-adapted configurational modelling of fractional site occupancy in solids. J. Phys.: Condens. Mat. 19, 256201.

Greegor R. B., Pingitore N. E. and Lytle F. W. (1997) Strontianite in coral skeletal aragonite. Science 275(5305), 1452-1454. 
Guggenheim E. A. (1937) The theoretical basis of Raoult's law. Trans. Faraday Soc. 33, 151-159.

Guilderson T. P., Fairbanks R. G. and Rubenstone J. L. (1994) Tropical temperature variations since 20,000 years agomodulating interhemispheric climate change. Science 263(5147), 663-665.

Holland H. D., Borcsik M., Munoz J. and Oxburgh U. M. (1963) The coprecipitation of $\mathrm{Sr}^{+2}$ with aragonite and of $\mathrm{Ca}^{+2}$ with strontianite between $90{ }^{\circ} \mathrm{C}$ and $100^{\circ} \mathrm{C}$. Geochim. Cosmochim. Acta 27, 957-964.

Lavrentiev M. Y., Allan N. L. and Purton J. A. (2003) Beyond the point defect limit: solid solutions, phase diagrams and traceelement partitioning. Phys. Chem. Chem. Phys. 5(11), 21902196.

Levi Y., Albeck S., Brack A., Weiner S. and Addadi L. (1998) Control over aragonite crystal nucleation and growth: an in vitro study of biomineralization. Chemistry 4(3), 389-396.

Lippmann F. (1980) Phase diagrams depicting aqueous solubility of binary mineral systems. Neues Jahrb. Mineral. Abh. 139(139), $1-25$.

Lucas-Girot A., Hernandez O. and Oudadesse H. (2007) Reexamination of the structural properties of solid solutions $\mathrm{Sr}_{x} \mathrm{Ca}_{1-x} \mathrm{CO}_{3}$. Mater. Res. Bull. 42(6), 1061-1068.

McCulloch M. T., Gagan M. K., Mortimer G. E., Chivas A. R. and Isdale P. J. (1994) A high-resolution Sr/Ca and Delta-O-18 coral record from the Great-Barrier-Reef, Australia, and the 1982-1983 El-Nino. Geochim. Cosmochim. Acta 58(12), 27472754.

McLean D. (1957) Grain boundaries in metals. Clarendon, Oxford.

Morse J. W. and Mackenzie F. T. (1990) Geochemistry of Sedimentary Carbonates. Elsevier.

Pavese A., Catti M., Price G. D. and Jackson R. A. (1992) Interatomic potentials for $\mathrm{CaCO}_{3}$ polymorphs (calcite and aragonite), fitted to elastic and vibrational data. Phys. Chem. Miner. 19(2), 80-87.

Pavese A., Catti M., Parker S. C. and Wall A. (1996) Modelling of the thermal dependence of structural and elastic properties of calcite, $\mathrm{CaCO}_{3}$. Phys. Chem. Miner. 23(2), 89-93.

Plummer L. N. and Busenberg E. (1987) Thermodynamics of aragonite-strontianite solid-solutions - results from stoichiometric solubility at 25-degrees-C and 76-degrees-C. Geochim. Cosmochim. Acta 51(6), 1393-1411.

Prieto M., Fernandez-Gonzalez A., Becker U. and Putnis A. (2000) Computing Lippmann diagrams from direct calculation of mixing properties of solid solutions: application to the baritecelestite system. Aquat. Geochem. 6(2), 133-146.

Schrag D. P. and Linsley B. K. (2002) Paleoclimate: corals, chemistry, and climate. Science 296(5566), 277-278.

Shannon R. D. (1976) Revised effective ionic radii and systematic studies of interatomic distances in halides and chalcogenides. Acta Crystallogr. A 32, 751-767.

Smith S. V., Buddemeier R. W., Redalje R. C. and Houck J. E. (1979) Strontium-calcium thermometry in coral skeletons. Science 204(4391), 404-407.

Speer, J.A. (1983) Crystal chemistry and phase relations of orthorhombic carbonates. In Carbonates: Mineralogy and Chemistry, vol. 11 (ed. R. J. Reeder). Mineral. Soc. Am., Rev. Mineral., pp. 145-190.

Taylor M. B., Barrera G. D., Allan N. L. and Barron T. H. K. (1997) Free-energy derivatives and structure optimization within quasiharmonic lattice dynamics. Phys. Rev. B 56(22), $14380-14390$

Todorov I. T., Allan N. L., Lavrentiev M. Y., Freeman C. L., Mohn C. E. and Purton J. A. (2004) Simulation of mineral solid solutions at zero and high pressure using lattice statics, lattice dynamics and Monte Carlo methods. J. Phys.: Condens. Mat. 16(27), S2751-S2770.

Weber J. N. (1973) Incorporation of strontium into reef coral skeletal carbonate. Geochim. Cosmochim. Acta 37(9), 21732190 .

Associate editor: Dimitri A. Sverjensky 